\title{
Association Between the Catechol-O-Methyltransferase Val I58Met Polymorphism and Cocaine Dependence
}

\author{
Falk W Lohoff*,', Andrew E Weller', Paul J Bloch', Aleksandra H Nall', Thomas N Ferraro', \\ Kyle M Kampman ${ }^{2}$, Helen M Pettinati ${ }^{2}$, David W Oslin ${ }^{2}$, Charles A Dackis ${ }^{2}$, Charles P O'Brien ${ }^{2}$ and \\ Wade H Berrettini'
}

'Department of Psychiatry, Translational Research Laboratories, Center for Neurobiology and Behavior, University of Pennsylvania School of Medicine, Philadelphia, PA, USA; ${ }^{2}$ Department of Psychiatry, Treatment Research Center, University of Pennsylvania School of Medicine, Philadelphia, PA, USA

\begin{abstract}
Dopaminergic brain systems have been documented to have a major role in drug reward, thus making genes involved in these circuits plausible candidates for susceptibility to substance use disorders. The catechol-O-methyltransferase (COMT) is involved in the degradation of catecholamines and a functional polymorphism (Val I 58Met) has been suggested to influence enzyme activity. In this study we hypothesize that genetic variation in the COMT gene contributes to increased risk for cocaine dependence. Cocaine-dependent individuals $(n=330)$ and screened unaffected normal controls $(n=255)$ were genotyped for three SNPs in the COMT gene (rs737865, rs4680 (Vall 58Met), rs I65599). All cases and controls were of African descent. Genotype and allele frequencies differed significantly for the Vall58Met polymorphism between cases $(\mathrm{f}(\mathrm{Met})=35 \%)$ and controls $(\mathrm{f}(\mathrm{Met})=27 \%)(p=0.004$; corrected $p=0.0 \mathrm{I} 4$; OR I.44; 95\% Cl I. I2-1.86). Haplotype analysis showed a significant association for a two-marker haplotype rs737865-Vall 58Met ( $p=0.005)$. Results suggest that variation in COMT increases risk for cocaine dependence. The low enzyme activity I58Met allele or haplotypes containing this variant might have functional effects on dopamine-derived reward processes and cortical functions resulting in increased susceptibility for cocaine dependence. Additional studies are required to elucidate the role of COMT in the pathophysiology of substance use disorders.
\end{abstract}

Neuropsychopharmacology (2008) 33, 3078-3084; doi:I0.1038/npp.2008. I26; published online I3 August 2008

Keywords: genetics; association study; haplotype; addiction; substance abuse

\section{INTRODUCTION}

Cocaine dependence is a devastating disorder with no FDAapproved pharmacological treatments available. Genetic studies estimate that $65-78 \%$ of the vulnerability risk for cocaine dependence is heritable (Kendler et al, 2000; Kendler and Prescott, 1998); however, identification of genetic risk factors remains difficult due to the complex mode of inheritance, clinical and genetic heterogeneity, and likely multiple genes involved, each contributing only a small effect to the overall risk. Dopaminergic brain systems have been documented to have a major role in drug reward (Dackis and O'Brien, 2005, 2001; Hyman et al, 2006), thus making genes involved in these circuits plausible candidates for susceptibility to substance use disorders (Lachman, 2006). The enzyme catechol-O-methyltransferase (COMT) is

*Correspondence: FW Lohoff, Department of Psychiatry, Translational Research Laboratories, Center for Neurobiology and Behavior, University of Pennsylvania School of Medicine, 125 South 3 I st Street, Philadelphia, PA 19104, USA, Tel: + | 215573 4582, Fax: + | 215573 204 I, E-mail: lohoff@mail.med.upenn.edu

Received 27 February 2008; revised 19 June 2008; accepted I5 July 2008 involved in the degradation of catecholamines, including dopamine (Axelrod and Tomchick, 1958). The functional COMT polymorphism Val158Met affects enzyme activity, with the Val allele resulting in higher enzyme activity relative to the Met allele (Aksoy et al, 1993; Boudikova et al, 1990; Lachman et al, 1996; Lotta et al, 1995; Spielman and Weinshilboum, 1981). Several studies suggest that the Val158Met polymorphism is involved in psychiatric phenotypes, including schizophrenia and bipolar disorder (Craddock et al, 2006; Tunbridge et al, 2006), and might further contribute to the comorbid substance abuse/ dependence spectrum across psychiatric disorders. Although cocaine blocks the dopamine transporter primarily, leading to enhanced postsynaptic effects of dopamine signaling, COMT remains an important regulatory element in dopamine homeostasis. Emerging evidence suggests that COMT variation influences prefrontal cortex (PFC) dopamine regulation and might modulate aspects of cognition, emotions, and behavior (Egan et al, 2001; Tunbridge et al, 2006). PFC dysfunction might be an important component in cocaine dependence that contributes to loss of control and denial (Dackis and O'Brien, 2005). Individual differences in COMT activity might therefore influence vulner- 
ability to cocaine dependence and other substance use disorders. In this study we tested the hypothesis that the functional Val158Met variation of the COMT gene increases susceptibility to cocaine dependence in individuals of African descent.

\section{MATERIALS AND METHODS}

DNA samples from cocaine-dependent individuals of African-American descent $(n=330 ; 72 \%$ male subjects, mean age: 43) were collected during clinical studies of cocaine dependence at the University of Pennsylvania Treatment Research Center. Subjects were at least 18 years of age and were all assessed with the Structured Clinical Interview for DSM Disorders and urine drug screens were obtained. All patients had a clinical diagnosis of cocaine dependence as defined by DSM-IV. Family history was not obtained and ethnicity was determined by self-report. Exclusion criteria were all psychiatric axis I disorders except alcohol dependence/abuse and nicotine dependence. In addition to these exclusion criteria, participants were excluded if they had a history of a seizure disorder (except cocaine-induced seizures) or a severe medical illness, including a history of AIDS (but not merely of HIV + status). Individuals currently being treated with psychotropic medications or with psychiatric symptoms, including psychosis, dementia, suicidal or homicidal ideation, mania or depression requiring antidepressant therapy were excluded from these studies. Control samples from persons of African descent $(n=255 ; 29 \%$ male subjects, mean age: 40) were collected at the University of Pennsylvania, Thomas Jefferson University and through the National Institute of Mental Health Genetics Initiative (www. nimhgenetics.org). Control individuals were screened for history of substance use disorders or other psychiatric illness. Control subjects were not assessed with a urine drug screen and ethnicity determination was by self-report. Subjects with a history of substance dependence or a history of major psychiatric illness (schizophrenia and unipolar or bipolar illnesses) as defined by DSM-IV criteria were excluded from this study (Berrettini and Persico, 1996). All protocols were approved by the Institutional Review Boards at Thomas Jefferson University and the University of Pennsylvania and all subjects provided written informed consent before DNA sample collection.

Genotyping of three SNPs across the COMT gene was performed using the Applied Biosystems Inc. (Foster City, CA, USA) 'Assays-on-demand' (ABI) SNP genotyping assay as per manufacturers protocol (SNP1: rs737865; SNP2: rs4680 (Val158Met); SNP3: rs165599). SNPs were selected based on findings in previous studies (Shifman et al, 2002), including studies of nicotine dependence in AfricanAmerican subjects (Berrettini et al, 2007) (Figure 1). Genotyping quality control was assured by genotyping $10 \%$ duplicates for cases and controls. Concordance rate of genotypes was $>99.5 \%$.

\section{Statistical Analyses}

Genotypes and allele frequencies were compared between groups using $\chi^{2}$ contingency analysis. A two-tailed type I error rate of $5 \%$ was chosen for the analysis. Linkage

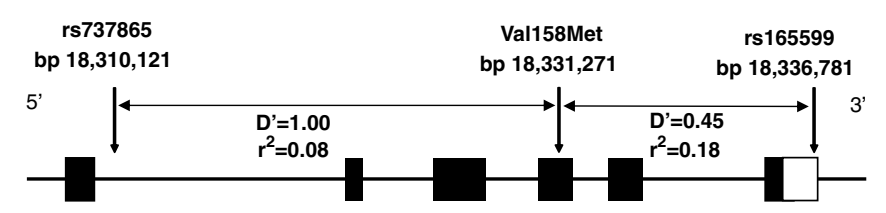

Figure I Diagram of the COMT gene and the three SNPs examined, with linkage disequilibrium $D^{\prime}$ values. Values in bp refer to chromosome 22, taken from the March 2006 assembly of the human genome sequence at www.genome.ucsc.edu. Exons are indicated by shaded boxes. The unshaded box represents the $3^{\prime}$ UTR in exon 6. D' values represent African-American sample results.

disequilibrium (LD) and haplotype frequencies were estimated using the COCAPHASE program (Dudbridge, 2003). The COCAPHASE program uses standard unconditional logistic regression analysis. Correction for multiple testing was performed using permutation correction by the COCAPHASE program. This approach corrects for multiple testing but takes into account the correlation between markers. It is thus less conservative than a Bonferroni correction, which is appropriate for independent tests such as unlinked markers. For the single-marker analyses, 10000 permutations were carried out to estimate the significance of the best results, correcting for the three loci tested. Haplotype analysis was performed using a two- and threemarker window. Rare haplotypes were excluded from analysis as the EM algorithm does not accurately estimate haplotype frequencies $<1 \%$ (Fallin and Schork, 2000). The most significant $p$-value was corrected by permutation analysis as described above.

Our sample size had reasonable power to detect a disease association at a $p$-value less than or equal to 0.05 , assuming an odds ratio of 1.5 and a minor allele frequency of $30 \%$ (99\% for a log-additive mode of inheritance, $92 \%$ for a dominant, and $56 \%$ for a recessive mode of inheritance). Power analysis was performed using the Quanto program (Gauderman, 2002).

\section{RESULTS}

None of the genotype counts deviated significantly from those expected from Hardy-Weinberg equilibrium for cases or controls. Genotype and allele frequencies differed significantly for the Val158Met polymorphism between cocaine-dependent individuals $(\mathrm{f}(\mathrm{Met})=35 \%)$ and normal controls $(\mathrm{f}(\mathrm{Met})=27 \%)(p=0.004$; corrected $p=0.014$; OR 1.44; 95\% CI 1.12-1.86). SNP1 and SNP3 did not show a statistical difference between cases and controls (Table 1). There was no significant gender effect for any of the tested SNPs. Allele frequencies were consistent with those reported in the literature for individuals of African descent (Berrettini et al, 2007). Haplotype analysis showed significant associations for two-marker analysis and a trend for the three-marker combination (Table 2); however, after correction for multiple testing only the rs737865-rs4680 haplotype remained statistically significant. The patient group carried the major allele of rs737865 and the Met158 allele more often (33\%) compared to controls (26\%) $(p=0.005$; corrected $p=0.02$; OR 1.44). Haplotype analysis results appear to be driven by the Val158Met SNP, 
Table I Genotype and Allele Frequencies of Variations in the COMT Gene

\begin{tabular}{|c|c|c|c|c|c|c|c|c|}
\hline \multirow{2}{*}{$\begin{array}{l}\text { SNP } \\
\text { rs737865 }\end{array}$} & \multirow[t]{2}{*}{ Sample } & \multirow[t]{2}{*}{$n$} & \multicolumn{3}{|c|}{ Genotype frequency } & \multirow[t]{2}{*}{$\boldsymbol{p}^{\mathrm{a}}$} & \multirow{2}{*}{$\begin{array}{c}\text { Allele frequency } \\
f(A)\end{array}$} & \multirow[t]{2}{*}{$p^{b}$} \\
\hline & & & A/A & $A / G$ & $\mathrm{G} / \mathrm{G}$ & & & \\
\hline & Cocaine & 330 & 0.715 & 0.255 & 0.030 & 0.312 & 0.842 & 0.766 \\
\hline & Controls & 253 & 0.688 & 0.296 & 0.016 & & 0.836 & \\
\hline \multirow[t]{2}{*}{ Vall58Met ${ }^{\mathrm{c}}$} & & & $\mathrm{Val} / \mathrm{Val}$ & $\mathrm{Val} / \mathrm{Met}$ & Met/Met & & $f($ Met $)$ & \\
\hline & Cocaine & 324 & 0.417 & 0.469 & 0.114 & 0.011 & 0.349 & $0.004^{d}$ \\
\hline \multirow[t]{3}{*}{ rs 65599} & & & A/A & $A / G$ & $\mathrm{G} / \mathrm{G}$ & & $f(A)$ & \\
\hline & Cocaine & 324 & 0.454 & 0.441 & 0.105 & 0.258 & 0.674 & 0.196 \\
\hline & Controls & 255 & 0.486 & 0.447 & 0.067 & & 0.710 & \\
\hline
\end{tabular}

aType I error rates for comparison of genotype frequencies between cocaine-dependent individuals and controls.

bType I error rates for comparison of allele frequencies between cocaine-dependent individuals and controls.

'Vall 58 Met $=r s 4680(\mathrm{Val}=\mathrm{G})$.

${ }^{\mathrm{d} G l o b a l}$ significance after permutation correction for multiple testing: $p=0.014$, standard error $(\mathrm{SE})=0.001$ । 75 .

Table 2 Analysis of Common Haplotypes in the COMT Gene

\begin{tabular}{|c|c|c|c|c|c|c|c|}
\hline Haplotype & Case & Frequency & Control & Frequency & OR & $\chi^{2}$ & $p$ \\
\hline \multicolumn{8}{|c|}{ rs $737865-r s 4680^{a}$} \\
\hline A-Val & 325 & 0.520 & 289 & 0.580 & 1 & 3.962 & 0.046 \\
\hline A-Met & 211 & 0.338 & 130 & 0.261 & 1.443 & 7.84 & 0.005 \\
\hline G-Val & 88 & 0.141 & 79 & 0.158 & 0.990 & 0.675 & 0.411 \\
\hline \multicolumn{8}{|c|}{ rs $4680^{a}-r s 165599$} \\
\hline Val-A & 341.5 & 0.542 & 308.2 & 0.604 & 1 & 4.547 & 0.032 \\
\hline Val-G & 73.51 & 0.116 & 63.77 & 0.125 & 1.04 & 0.277 & 0.598 \\
\hline Met-A & 86.51 & 0.137 & 53.77 & 0.105 & 1.452 & 2.829 & 0.092 \\
\hline Met-G & 128.5 & 0.204 & 84.23 & 0.165 & 1.377 & 3.282 & 0.070 \\
\hline \multicolumn{8}{|c|}{ rs737865-rs / 65599} \\
\hline$A-A$ & 358.8 & 0.555 & 295.2 & 0.583 & 1 & 0.879 & 0.348 \\
\hline$A-G$ & 184.2 & 0.285 & 127.8 & 0.252 & 1.186 & 1.535 & 0.215 \\
\hline G-A & 76.22 & 0.118 & 62.81 & 0.124 & 0.998 & 0.175 & 0.675 \\
\hline G-G & 26.78 & 0.041 & 20.19 & 0.039 & 1.091 & 0.107 & 0.742 \\
\hline \multicolumn{8}{|c|}{ rs737865-rs4680a -rs 165599} \\
\hline A-Val-A & 259.6 & 0.437 & 230.7 & 0.470 & I & 1.274 & 0.259 \\
\hline A-Val-G & 59.42 & 0.10 & 57.27 & 0.116 & 0.922 & 0.929 & 0.335 \\
\hline A-Met-A & 78.42 & 0.132 & 47.27 & 0.096 & 1.475 & 3.673 & 0.055 \\
\hline A-Met-G & 120.6 & 0.203 & 81.73 & 0.166 & 1.311 & 2.566 & 0.109 \\
\hline G-Val-A & 76 & 0.127 & 73 & 0.149 & 0.925 & 0.998 & 0.317 \\
\hline
\end{tabular}

Best $p$-value 0.0051 I; global significance after permutation correction: $p=0.0263, \mathrm{SE}=0.0016$.

$a_{r s 4680}=\operatorname{Vall} 58 \mathrm{Met}(\mathrm{Val}=\mathrm{G})=\mathrm{rs} 4680$.

supporting the hypothesis that the Val158Met polymorphism is a causative functional SNP.

\section{DISCUSSION}

In the present study, we show an association between the Val158Met polymorphism of the COMT gene and cocaine dependence in individuals of African descent. Furthermore, we identify a risk haplotype contributing to the susceptibility for cocaine dependence. To our knowledge, this is the first report of an association of the COMT Val158Met polymorphism in cocaine dependence in individuals of African descent; however, given the high comorbidity of polysubstance abuse in individuals using cocaine, our result might reflect an association of a broader phenotype of substance use disorders. In fact, several previous studies have implicated the Val158Met polymorphism in a variety of substance abuse disorders (Table 3) (Beuten et al, 2005; Enoch et al, 2006; Horowitz et al, 2000; Hosak et al, 2006; Li et al, 2004; Samochowiec et al, 2006; Sery et al, 2006; Tiihonen et al, 1999; Vandenbergh et al, 2000, 1997; Wang et al, 2001); however, others could not replicate results (Cevoli et al, 2006; Guo et al, 2007; Hallikainen et al, 2000; Kauhanen et al, 2000; Kweon et al, 2005) and there is no clear consensus on whether the Val allele or the Met allele increases risk (Table 3 ). This locus heterogeneity might indicate that the COMT Val158Met polymorphism is only one important variation in a cascade of regulatory systems, and depending on other genes or environmental factors, a higher or lower enzyme activity might predispose to substance use disorders. The COMT Val158Met polymorphism, rather then a single allele, might thus have an effect on pathways commonly shared between all substance use disorders. Such pathways include the reward system and cognitive functions influencing substance use behavior.

Dysregulation of COMT, which is the major enzyme involved in the degradation of dopamine in the frontal cortex (Karoum et al, 1994), might have primarily effects on cognitive processes involved in substance dependence and indirect downstream effects on the reward system, as suggested by recent neuroimaging data (Goldstein and Volkow, 2002; Volkow et al, 2002). Our results suggest an increased Met allele (low activity allele) frequency in cocaine users $(35 \%)$ compared to normal controls $(27 \%)$ $(p=0.004$; corrected $p=0.014)$ in individuals of African descent. This finding is in line with the results of Hosak et al (2006) who showed higher novelty seeking scores in methamphetamine-dependent individuals with a Met allele (Hosak et al, 2006) and the observation that Met/Met 
Table 3 Case-Control Association Studies of the COMT Vall58Met Polymorphism in Substance Use Disorders

\begin{tabular}{|c|c|c|c|c|c|c|c|}
\hline Author & Year & $\begin{array}{l}\text { Substance use } \\
\text { disorder }\end{array}$ & Ethnicity & $\begin{array}{l}\text { Sample size } \\
\text { (n) }\end{array}$ & $\begin{array}{l}\text { Val I58 } \\
\text { frequency }\end{array}$ & $\begin{array}{l}\text { Met I58 } \\
\text { frequency }\end{array}$ & $\begin{array}{l}p \text {-value allele } \\
\text { frequency }\end{array}$ \\
\hline Ishiguro et al & 1999 & Alcohol dependence & Japanese & Cases (175) & 0.70 & 0.30 & NS \\
\hline \multirow[t]{2}{*}{ Tiihonen et al } & 1999 & Alcohol dependence & Finnish & Cases (123) & 0.39 & 0.61 & $p<0.05^{\mathrm{a}}$ \\
\hline & & & & Controls (267) & 0.49 & 0.51 & \\
\hline \multirow[t]{2}{*}{ Kweon et al } & 2005 & Alcohol dependence & Korean & Cases (97) & 0.74 & 0.25 & $N S^{c}$ \\
\hline & & & & Controls (94) & 0.70 & 0.29 & \\
\hline \multirow[t]{2}{*}{ Samochowiec et al } & 2006 & Alcohol dependence & Polish & Cases $(100)$ & Not reported & Not reported & NS \\
\hline & & & & Controls (196) & & & \\
\hline Sery et al & 2006 & Alcohol dependence & Czech & Cases (339) & 0.52 & 0.48 & $N S^{d}$ \\
\hline \multirow[t]{2}{*}{ Li et al } & 2004 & Methamphetamine abuse & Chinese & Cases $(416)$ & 0.74 & 0.26 & $p=0.02$ \\
\hline & & & & Controls (435) & 0.68 & 0.32 & \\
\hline \multirow[t]{2}{*}{ Suzuki et al } & 2006 & $\begin{array}{l}\text { Methamphetamine abuse } \\
\text { (psychosis) }\end{array}$ & Japanese & Cases (143) & 0.68 & 0.31 & NS \\
\hline & & & & Controls (200) & 0.62 & 0.37 & \\
\hline \multirow[t]{2}{*}{ Guo et al } & 2007 & Nicotine dependence & Chinese & Cases (203) & 0.78 & 0.21 & $N S^{g}$ \\
\hline & & & & Controls (102) & 0.72 & 0.27 & \\
\hline \multirow[t]{2}{*}{ Vandenbergh et al } & 1997 & $\begin{array}{l}\text { Polysubstance abuse } \\
\text { (lifetime use) }\end{array}$ & Caucasian & Cases (185) & 0.54 & 0.46 & $p=0.02$ \\
\hline & & & & Controls (124) & 0.44 & 0.56 & \\
\hline
\end{tabular}

Abbreviation: NS, not significant.

aThis study also compared the allele frequency of the cases to the general population $(n=3 \mid 40)$. The difference in allele frequency was significant $(p<0.05)$.

${ }^{\mathrm{b}}$ This study supplemented the 5 I Tiihonen et al study. Although 5 I Tiihonen et al used type I alcohol-dependent cases, this study used type 2 alcohol-dependent cases.

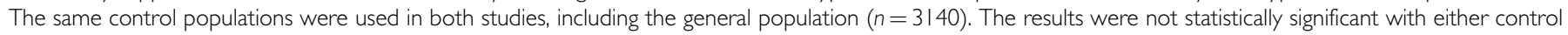
population.

"When subdividing alcoholic cases by violent behavior, a significant allele frequency difference was observed between violent alcoholics and nonviolent alcoholics ( $p=0.012)$ as well as controls and nonviolent alcoholics $(p=0.04)$.

When subdividing populations by sex, a significant allele frequency difference was observed between male alcoholics and male controls ( $p<0.007$ ).

"Israeli includes both Palestinian Arabs and Israeli Jews.

${ }^{f}$ Family-based haplotype relative risk design implemented with allelic frequency $(p=0.03)$.

'This study also genotyped former smokers $(n=66)$. No association was indicated.

carriers have decreased efficiency of PFC information processing in response amphetamine (Mattay et al, 2003). Individuals with the low-activity COMT allele may have longer-lasting and more effective dopamine release in the brain, in particular in the PFC affecting higher cortical functions involved in substance use behavior.

Although our study provides evidence for an association between the Val158Met polymorphism and cocaine dependence, it could be possible that other variations that are in LD with the Val158Met SNP might contribute to the observed association or that a haplotype confers risk rather then a single SNP. Consistent with this possibility are several studies that found haplotypes to be associated with disease rather than with a single polymorphism (Berrettini et al, 2007; Shifman et al, 2002). Recent reports show that COMT haplotypes code for differences in enzyme activity (Diatchenko et al, 2005) and haplotype-specific mRNA secondary structure has functional effects on COMT protein synthesis and enzyme activity (Nackley et al, 2006). Our haplotype analysis indicates a risk haplotype for rs737865 and Val158Met $(p=0.005$; corrected $p=0.02$; OR 1.44). Interestingly, both markers (rs737865 and Val158Met) are in strong LD and incorporate the SNPs in the functional haplotypes described by Nackley et al (2006). Additional studies are necessary to elucidate potential functional haplotypic variations. Furthermore, it might be necessary to investigate this chromosomal region in more depth, given recent evidence of copy-number variations in this region (Wong et al, 2007) and the close proximity of COMT to other interesting candidate genes, like ARVCF, a member of the catenin family, which is involved in cell-cell communication.

Even though we report a positive association between the COMT gene and cocaine dependence, it is possible that our finding might be a false-positive result due to population stratification. Case-control association studies of subjects with self-reported ancestries are not immune to population stratification (Freedman et al, 2004). Undetected differences 
in population structure can mimic the signal of association and lead to false-positive results or real effects that are missed (Pritchard and Donnelly, 2001). This is a particular concern for analyses of samples of African-American descent, as recent studies indicate larger genetic admixture than previously thought (Parra et al, 2001; Pfaff et al, 2001; Tian et al, 2006; Zhu et al, 2004). In fact, the Met allele is less frequent in individuals of African descent (Ameyaw et al, 2000; DeMille et al, 2002; McLeod et al, 1994), and haplotypes in COMT show marked differences across populations (Palmatier et al, 1999). Possible strategies to control for these stratification issues are the use of genomic controls (Bacanu et al, 2000; Devlin and Roeder, 1999) and/ or the use of a family-based association design, a strategy that matches the genotype of an affected offspring with parental alleles not inherited by the offspring (Spielman and Ewens, 1996). In addition to these potential issues of genetic heterogeneity and population stratification, it is also important to consider limitations of clinical heterogeneity. All patients were diagnosed according to DSM-IV criteria; however, comorbid use of alcohol and nicotine might have differed between patients. Furthermore, the control subjects were assessed using semistructured interviews but did not undergo urine drug testing. Although drug testing is useful in establishing a diagnosis, it might not be useful for assessment of controls as it does not rule out past exposure or substance use. Unreported or minimized substance abuse in the control population is thus an important limitation that needs to be considered. Finally, spurious positive association findings remain a valid concern as recently shown in a statistical simulation study of the COMT gene (Sullivan, 2007). Thus, our results should be interpreted with caution and ultimately require careful replication and confirmation in an independent population of patients and controls.

In summary, we show that the Val158Met polymorphism in the COMT gene is associated with cocaine dependence. In addition we have identified a COMT risk haplotype for cocaine dependence. Our results require confirmation in other populations, and additional studies are required to elucidate the role of COMT in the pathophysiology of substance use disorders.

\section{ACKNOWLEDGEMENTS}

This work was supported by the center for neurobiology and behavior, department of psychiatry, University of Pennsylvania. Financial support is gratefully acknowledged from national institutes of health grants MH59553, MH63876 (WHB), T32MH014654-29A1 (FWL), NIDA GRANTS P60-051186 (CPO) and P50-12756 (HMP), the VISN4 Mental Illness Research and Clinical Center grant from the Veterans Affairs Administration (DWO), grants from the National Alliance for Research on Schizophrenia and Depression (WHB), a grant from the Tzedakah Foundation (WHB), the Daland Fellowship Award by the American Philosophical Society (FWL), and a grant from Philip and Marcia Cohen (WHB). We thank Candice Schwebel for technical assistance. Most importantly, we thank the patients who participated in and contributed to these studies. The NIMH control subjects were collected by the NIMH Schizophrenia Genetics Initiative 'Molecular Genetics of Schizophrenia II' (MGS-2) collaboration. The investigators and co-investigators are: $\mathrm{ENH} /$ Northwestern University, Evanston, IL, MH059571 - Pablo V Gejman (collaboration coordinator; PI), Alan R Sanders; Emory University School of Medicine, Atlanta, GA, MH59587-Farooq Amin (PI); Louisiana State University Health Sciences Center, New Orleans, LA, MH067257-Nancy Buccola APRN (PI); University of California, Irvine, Irvine, CA, MH60870-William Byerley (PI); Washington University, St Louis, MO, U01, MH060879 - C Robert Cloninger (PI); University of Iowa, Iowa, IA, MH59566-Raymond Crowe (PI), Donald Black; University of Colorado, Denver, CO, MH059565-Robert Freedman (PI); University of Pennsylvania, Philadelphia, PA, MH061675-Douglas Levinson (PI); University of Queensland, QLD, Australia, MH059588-Bryan Mowry (PI); and Mt Sinai School of Medicine, New York, NY, MH59586-Jeremy Silverman (PI).

\section{CONFLICT OF INTEREST/DISCLOSURE}

The authors FWL, AEW, PJB, AHN, TNF, KMK, DWO, HMP, CAD, CPO, and WHB reported no biomedical financial interests or potential conflicts of interest.

\section{REFERENCES}

Aksoy S, Klener J, Weinshilboum RM (1993). Catechol $O$-methyltransferase pharmacogenetics: photoaffinity labelling and western blot analysis of human liver samples. Pharmacogenetics 3: 116-122.

Ameyaw MM, Syvanen AC, Ulmanen I, Ofori-Adjei D, McLeod HL (2000). Pharmacogenetics of catechol-O-methyltransferase: frequency of low activity allele in a Ghanaian population. Hum Mutat 16: 445-446.

Axelrod J, Tomchick R (1958). Enzymatic O-methylation of epinephrine and other catechols. J Biol Chem 233: 702-705.

Bacanu SA, Devlin B, Roeder K (2000). The power of genomic control. Am J Hum Genet 66: 1933-1944.

Berrettini WH, Persico AM (1996). Dopamine D2 receptor gene polymorphisms and vulnerability to substance abuse in African Americans. Biol Psychiatry 40: 144-147.

Berrettini WH, Wileyto EP, Epstein L, Restine S, Hawk L, Shields P et al (2007). Catechol-O-methyltransferase (COMT) gene variants predict response to bupropion therapy for tobacco dependence. Biol Psychiatry 61: 111-118.

Beuten J, Payne TJ, Ma JZ, Li MD (2005). Significant association of catechol-O-methyltransferase (COMT) haplotypes with nicotine dependence in male and female smokers of two ethnic populations. 31: 675-684.

Boudikova B, Szumlanski C, Maidak B, Weinshilboum R (1990). Human liver catechol-O-methyltransferase pharmacogenetics. Clin Pharmacol Ther 48: 381-389.

Cevoli S, Mochi M, Scapoli C, Marzocchi N, Pierangeli G, Pini LA et al (2006). A genetic association study of dopamine metabolism-related genes and chronic headache with drug abuse. Eur J Neurol 13: 1009-1013.

Craddock N, Owen MJ, O'Donovan MC (2006). The catechol-Omethyl transferase (COMT) gene as a candidate for psychiatric phenotypes: evidence and lessons. Mol Psychiatry 11: 446-458.

Dackis C, O'Brien C (2005). Neurobiology of addiction: treatment and public policy ramifications. Nat Neurosci 8: 1431-1436.

Dackis CA, O'Brien CP (2001). Cocaine dependence: a disease of the brain's reward centers. J Subst Abuse Treat 21: 111-117. 
DeMille MM, Kidd JR, Ruggeri V, Palmatier MA, Goldman D, Odunsi A et al (2002). Population variation in linkage disequilibrium across the COMT gene considering promoter region and coding region variation. Hum Genet 111: 521-537.

Devlin B, Roeder K (1999). Genomic control for association studies. Biometrics 55: 997-1004.

Diatchenko L, Slade GD, Nackley AG, Bhalang K, Sigurdsson A, Belfer I et al (2005). Genetic basis for individual variations in pain perception and the development of a chronic pain condition. Hum Mol Genet 14: 135-143.

Dudbridge F (2003). Pedigree disequilibrium tests for multilocus haplotypes. Genet Epidemiol 25: 115-121.

Egan MF, Goldberg TE, Kolachana BS, Callicott JH, Mazzanti CM, Straub RE et al (2001). Effect of COMT Val108/158 Met genotype on frontal lobe function and risk for schizophrenia. Proc Natl Acad Sci USA 98: 6917-6922.

Enoch M-A, Waheed JF, Harris CR, Albaugh B, Goldman D (2006). Sex differences in the influence of COMT Val158Met on alcoholism and smoking in plains American Indians. Alcohol Clin Exp Res 30: 399-406.

Fallin D, Schork NJ (2000). Accuracy of haplotype frequency estimation for biallelic loci, via the expectation-maximization algorithm for unphased diploid genotype data. Am J Hum Genet 67: 947-959.

Freedman ML, Reich D, Penney KL, McDonald GJ, Mignault AA, Patterson $\mathrm{N}$ et al (2004). Assessing the impact of population stratification on genetic association studies. Nat Genet 36: 388-393.

Gauderman WJ (2002). Sample size requirements for association studies of gene-gene interaction. Am J Epidemiol 155: 478-484.

Goldstein RZ, Volkow ND (2002). Drug addiction and its underlying neurobiological basis: neuroimaging evidence for the involvement of the frontal cortex. Am J Psychiatry 159: $1642-1652$.

Guo S, Chen DF, Zhou DF, Sun HQ, Wu GY, Haile CN et al (2007). Association of functional catechol $O$-methyl transferase (COMT) Val108Met polymorphism with smoking severity and age of smoking initiation in Chinese male smokers. Psychopharmacology 190: 449-456.

Hallikainen T, Lachman H, Saito T, Volavka J, Kauhanen J, Salonen JT et al (2000). Lack of association between the functional variant of the catechol-o-methyltransferase (COMT) gene and early-onset alcoholism associated with severe antisocial behavior. Am J Med Genet 96: 348-352.

Horowitz R, Kotler M, Shufman E, Aharoni S, Kremer I, Cohen H et al (2000). Confirmation of an excess of the high enzyme activity COMT val allele in heroin addicts in a family-based haplotype relative risk study. Am J Med Genet 96: 599-603.

Hosak L, Libiger J, Cizek J, Beranek M, Cermakova E (2006). The COMT Val158Met polymorphism is associated with novelty seeking in Czech methamphetamine abusers: preliminary results. Neuro Endocrinol Lett 27: 799-802.

Hyman SE, Malenka RC, Nestler EJ (2006). Neural mechanisms of addiction: the role of reward-related learning and memory. Annu Rev Neurosci 29: 565-598.

Ishiguro H, Haruo Shibuya T, Toru M, Saito T, Arinami T (1999). Association study between high and low activity polymorphism of catechol-O-methyltransferase gene and alcoholism. Psychiatr Genet 9: 135-138.

Karoum F, Chrapusta SJ, Egan MF (1994). 3-Methoxytyramine is the major metabolite of released dopamine in the rat frontal cortex: reassessment of the effects of antipsychotics on the dynamics of dopamine release and metabolism in the frontal cortex, nucleus accumbens, and striatum by a simple two pool model. J Neurochem 63: 972-979.

Kauhanen J, Hallikainen T, Tuomainen TP, Koulu M, Karvonen MK, Salonen JT et al (2000). Association between the functional polymorphism of catechol-O-methyltransferase gene and alcohol consumption among social drinkers. Alcohol Clin Exp Res 24: 135-139.

Kendler KS, Karkowski LM, Neale MC, Prescott CA (2000). Illicit psychoactive substance use, heavy use, abuse, and dependence in a US population-based sample of male twins. Arch Gen Psychiatry 57: 261-269.

Kendler KS, Prescott CA (1998). Cocaine use, abuse and dependence in a population-based sample of female twins. $\mathrm{Br} \mathrm{J}$ Psychiatry 173: 345-350.

Kweon YS, Lee HK, Lee CT, Pae CU (2005). Association study of catechol-O-methyltransferase gene polymorphism in Korean male alcoholics. Psychiatr Genet 15: 151-154.

Lachman HM (2006). An overview of the genetics of substance use disorders. Curr Psychiatry Rep 8: 133-143.

Lachman HM, Papolos DF, Saito T, Yu YM, Szumlanski CL, Weinshilboum RM (1996). Human catechol-O-methyltransferase pharmacogenetics: description of a functional polymorphism and its potential application to neuropsychiatric disorders. Pharmacogenetics 6: 243-250.

Li T, Chen CK, Ball D, Lin SK, Chen W, Sham PC et al (2004). Association analysis of the DRD4 and COMT genes in methamphetamine abuse. Am J Med Genet B Neuropsychiatr Genet 129: 120-124.

Lotta T, Vidgren J, Tilgmann C, Ulmanen I, Melen K, Julkunen I et al (1995). Kinetics of human soluble and membrane-bound catechol $O$-methyltransferase: a revised mechanism and description of the thermolabile variant of the enzyme. Biochemistry 34: 4202-4210.

Mattay VS, Goldberg TE, Fera F, Hariri AR, Tessitore A, Egan MF et al (2003). Catechol $O$-methyltransferase val158-met genotype and individual variation in the brain response to amphetamine. Proc Natl Acad Sci USA 100: 6186-6191.

McLeod HL, Fang L, Luo X, Scott EP, Evans WE (1994). Ethnic differences in erythrocyte catechol-O-methyltransferase activity in black and white Americans. J Pharmacol Exp Ther 270: $26-29$.

Nackley AG, Shabalina SA, Tchivileva IE, Satterfield K, Korchynskyi O, Makarov SS et al (2006). Human catechol-Omethyltransferase haplotypes modulate protein expression by altering mRNA secondary structure. Science 314: 1930-1933.

Palmatier MA, Kang AM, Kidd KK (1999). Global variation in the frequencies of functionally different catechol- $O$-methyltransferase alleles. Biol Psychiatry 46: 557-567.

Parra EJ, Kittles RA, Argyropoulos G, Pfaff CL, Hiester K, Bonilla C et al (2001). Ancestral proportions and admixture dynamics in geographically defined African Americans living in South Carolina. Am J Phys Anthropol 114: 18-29.

Pfaff CL, Parra EJ, Bonilla C, Hiester K, McKeigue PM, Kamboh MI et al (2001). Population structure in admixed populations: effect of admixture dynamics on the pattern of linkage disequilibrium. Am J Hum Genet 68: 198-207.

Pritchard JK, Donnelly P (2001). Case-control studies of association in structured or admixed populations. Theor Popul Biol 60: 227-237.

Samochowiec J, Kucharska-Mazur J, Grzywacz A, łoñski M, Rommelspacher H, Samochowiec A et al (2006). Familybased and case-control study of DRD2, DAT, 5HTT, COMT genes polymorphisms in alcohol dependence. Neurosci Lett 410: $1-5$.

Sery O, Didden W, Mikes V, Pitelova R, Znojil V, Zvolsky P (2006). The association between high-activity COMT allele and alcoholism. Neuro Endocrinol Lett 27: 231-235.

Shifman S, Bronstein M, Sternfeld M, Pisanté-Shalom A, LevLehman E, Weizman A et al (2002). A highly significant association between a COMT haplotype and schizophrenia. Am J Hum Genet 71: 1296-1302. 
Spielman RS, Ewens WJ (1996). The TDT and other family-based tests for linkage disequilibrium and association. Am J Hum Genet 59: 983-989.

Spielman RS, Weinshilboum RM (1981). Genetics of red cell COMT activity: analysis of thermal stability and family data. Am J Med Genet 10: 279-290.

Sullivan PF (2007). Spurious genetic associations. Biol Psychiatry 61: 1121-1126.

Suzuki A, Nakamura K, Sekine Y, Minabe Y, Takei N, Suzuki K et al (2006). An association study between catechol-O-methyl transferase gene polymorphism and methamphetamine psychotic disorder. Psychiatr Genet 16: 133-138.

Tian C, Hinds DA, Shigeta R, Kittles R, Ballinger DG, Seldin MF (2006). A genomewide single-nucleotide-polymorphism panel with high ancestry information for African American admixture mapping. Am J Hum Genet 79: 640-649.

Tiihonen J, Hallikainen T, Lachman H, Saito T, Volavka J, Kauhanen J et al (1999). Association between the functional variant of the catechol-O-methyltransferase (COMT) gene and type 1 alcoholism. Mol Psychiatry 4: 286-289.

Tunbridge EM, Harrison PJ, Weinberger DR (2006). Catechol-omethyltransferase, cognition, and psychosis: Val158Met and beyond. Biol Psychiatry 60: 141-151.
Vandenbergh DJ, Rodriguez LA, Hivert E, Schiller JH, Villareal G, Pugh EW et al (2000). Long forms of the dopamine receptor (DRD4) gene VNTR are more prevalent in substance abusers: no interaction with functional alleles of the catechol-o-methyltransferase (COMT) gene. Am J Med Genet 96: 678-683.

Vandenbergh DJ, Rodriguez LA, Miller IT, Uhl GR, Lachman HM (1997). High-activity catechol-O-methyltransferase allele is more prevalent in polysubstance abusers. Am J Med Genet 74: 439-442.

Volkow ND, Fowler JS, Wang G-J, Goldstein RZ (2002). Role of dopamine, the frontal cortex and memory circuits in drug addiction: insight from imaging studies. Neurobiol Learn Mem 78: $610-624$.

Wang T, Franke P, Neidt H, Cichon S, Knapp M, Lichtermann D et al (2001). Association study of the low-activity allele of catechol-O-methyltransferase and alcoholism using a familybased approach. Mol Psychiatry 6: 109-111.

Wong KK, deLeeuw RJ, Dosanjh NS, Kimm LR, Cheng Z, Horsman $\mathrm{DE}$ et al (2007). A comprehensive analysis of common copy-number variations in the human genome. Am J Hum Genet 80: 91-104.

Zhu X, Cooper RS, Elston RC (2004). Linkage analysis of a complex disease through use of admixed populations. Am J Hum Genet 74: 1136-1153. 